\title{
Radiological impact associated with the transport by road of radioactive material in Spain
}

\author{
J.A. CALLEJA ${ }^{1}$, F. GUTIERREZ ${ }^{2}$
}

(Manuscript received 23 September 2010, accepted 4 April 2011)

ABSTRACT Questions relating to the transport of radioactive materials are very much an issue of current interest due to the increasing mobility of the materials involved in the nuclear fuel cycle, commitment to the environment, the safety and protection of persons and the corresponding regulatory legal framework. The radiological impact associated with this type of transport was assessed by means of a new dataprocessing tool that may be of use and serve as complementary documentation to that included in transport regulations. Thus, by determining the level of radiation at a distance of one metre from the transport vehicle and by selecting a route, the associated impacts will be obtained, such as the affected populations, the dose received by the most highly exposed individual, the overall radiological impact, the doses received by the population along the route and the possible detriment to their health. The most important conclusion is that the emissions of ionising radiation from the transport of radioactive material by road in Spain are not significant as regards the generation of adverse effects on human health, and that their radiological impact may be considered negligible.

Keywords: Detriment to health / personal dosimetry / radiological impact / radioactive material / radiological protection

RÉSUMÉ Impact radiologique lié au transport par route de matières radioactives en Espagne. Les questions liées aux transports des matériaux radioactifs sont d'actualité, à cause de l'augmentatrion de la mobilité des matières nucléaires dans le cycle du combustible, de l'implication sur l'environnement, de la sécurité et la protection des personnes, et du cadre réglementaire légal. L'impact radiologique associé à ce type de transport a été évalué par le biais d'un nouvel outil de traitement de données, qui peut être d'utilité et servir comme documentation complémentaire de celle puisée dans le cadre de la règlementation légale de transport. Ainsi, ayant connaissance du niveau de radiation à un mètre du véhicule et en choisissant la route, nous obtiendrons les impacts associés, tels que, les populations affectées, la dose reçue par la personne la plus exposée, l'impact radiologique global, la dose reçue par la population durant le trajet et le possible préjudice sanitaire. Comme conclusion, on observe que les émissions de radiation ionisantes en provenance du transport de matières radioactives par route en Espagne, ne sont pas significatives au regard de la production d'effets indésirables pour la santé humaine et que leur impact radiologique peut être considéré comme négligeable.

1 TECNATOM, Prevention Service, Avenida Montes de Oca 1, 28703 San Sebastián de los Reyes, Madrid, Spain.

(EUITI), Dept. Electrical Engineering, Polytechnic University of Madrid, Spain.

2 EUITI, Dept. Industrial and Polymer Chemistry, Polytechnic University of Madrid, Madrid, Spain. 


\section{Introduction}

In the transport of the radioactive materials involved in the nuclear fuel cycle or of other such materials (e.g. nuclear fuel, inspection equipment, radioactive sources, radioactive wastes, etc.), the safety of the materials, the protection of persons (Law $31 / 95$, 1995), commitment to the environment and compliance with the legal standards are of fundamental importance.

The following questions may be asked: which are the busiest routes? What radiological impact is generated on the environment or on persons, the occupants of a private vehicle, the general public...?

In Spain there are more than 10000 kilometres of "radioactive transport routes". Nuclear fuel is transported by road from the Juzbado fuel assembly manufacturing facility in the province of Salamanca to the nuclear power plants, and from here the low and intermediate level radioactive wastes generated are transported, also by road, to the El Cabril disposal facility in the province of Córdoba. The transport operations to or from the nuclear power plants and involving the equipment and materials necessary for the correct operation of these facilities should also be taken into consideration.

\section{Regulation of the road transport of radioactive material}

In Spain the transport of radioactive material is regulated by a series of internationally applicable standards based on the regulation for the safe transport of radioactive materials of the international atomic energy agency, IAEA (ADR, 2007). In all these standards the safety of the transport operations is based fundamentally on the packaging, of which there are different types (exempted, industrial, Type A, Type B and Type C) and design criteria are established relating both to the level of activity and to the physical form of the radioactive materials contained therein. Also detailed are the precautions to be taken as regards signposting and labelling and the requirements relating to the packaging during transport.

In order to ensure radiological protection and the prevention of environmental risks, limits are applied in relation to the intensity of the radiation and the contamination on the surface of the packaging and vehicles. The levels of activity transported are also limited. Another fundamental requirement is the supervision and control carried out by the safety counsellors (RD 566, 1999). 


\section{Assessment methodology}

The methodology used in preparing this work is based on the 'descriptiveexplanatory' method, which allows data to be observed and acquired by means of the 'case study' approach (Chetty, 1996; Yin, 1994). The aim of this method is to systematically describe the logistics of the road transport of radioactive material and the radiological impact associated with it by using direct and indirect sources. For the first of these, several companies have collaborated (the Spanish nuclear power plants: Cofrentes, Garoña, Vandellós II, Trillo, Almaraz, Ascó (Spanish NPP, 1995) and José Cabrera, the latter having been declared definitively shut down, the national radioactive waste management company empresa nacional de residuos radiactivos (ENRESA), installations such as Tecnatom, S.A. and the transport company E.T.S.A.). In order to identify the regulations governing permits and arrangements for radioactive material road transport operations, official organisations (the spanish nuclear regulatory body) were also consulted.

The nuclear fuel cycle has been selected due to its being the most representative area as regards radioactive transport operations, because of the control exercised over it by the competent authorities, the particularly important set of standards by which it is governed and for its significance for national energy development.

In Spain new fuel assemblies are transported to the nuclear power plants. Here, preventive maintenance and inspection activities are carried out in order to ensure the correct operation of the facilities, and the equipment and materials used occasionally become contaminated, as a result of which they must be transported as radioactive materials.

To a lesser extent, specimens and samples of irradiated materials and sources of different isotopes from research centres, used in different tests to observe the behaviour of different materials in response to ionising radiation, are also transported as radioactive materials.

Radioactive wastes and waste products or materials (Law 54/97, 1997) are also transported. These materials contain or are contaminated with radionuclides at concentrations of activity that sometimes exceed the levels established in the legislation. Low and intermediate level wastes (GRWP, 2006) have low concentrations of radioactive material, due fundamentally to the presence of radionuclides with a half-life of under 30 years and very low and limited contents of long-lived elements. High level wastes, mainly consisting of the spent fuel from the nuclear power plants, are temporarily stored underwater in the plant pools for cooling and, since 2002, in metallic dry storage casks at the so-called 
individualised temporary storage (ITS) facilities, as a result of which this type of waste is not currently transported.

\section{Dose assessment}

Although the aim of this paper is to assess the radiological risk for persons resulting from the emission of ionising radiation associated with the transport of radioactive materials, we are also interested in gaining insight into the probability of risk to their health. Ionising radiation produces ionisation upon passing through the tissues of living organisms. This ionisation upsets the chemical behaviour of the constituents of the affected cells; some of these may regenerate while others may be damaged. It should be borne in mind that the exposed individual is not bound to suffer cancer or genetic injury, but simply runs a higher risk of doing so than non-irradiated persons. This risk increases with dose (Ortega and Jorba, 1988).

In order to be able to make generally applicable estimates, the International Commission on Radiological Protection recommends a series of risk values, obtained for the populations of different countries and continents (ICRP, 1999), "the average of these values as regards the probability of death by cancer is $5 \%$ per Sievert in a population of all ages, as long as the dose and dose rates in question are low".

The spanish nuclear regulatory body (CSN) and the Carlos III institute of health (ISCIII) have carried out an "epidemiological study of the possible effects of ionising radiation arising from the operation of the Spanish nuclear fuel cycle nuclear and radioactive facilities on the health of the population residing in areas surrounding such installations" (Nuclear Safety Council, 2010), which we shall use as a reference.

\section{Radiological impact of the transport by road of radioactive materials in Spain}

The negative impact associated with this type of transport affects the environment, especially the living organisms exposed, and in particular the health of persons.

Work began with the selection of a representative year in terms of the volume of transport operations performed (2007, the year of the heaviest traffic associated with the nuclear fuel cycle in the last decade) (Chetty, 1996), a conservative situation being chosen for comparison with other years of interest. The level of traffic in question was the result of the scheduled refuelling outages that occurred at all the Spanish nuclear power plants during the year, a situation that will not 
occur again until 2011. There were a larger number of transport operations involving fuel, inspection equipment, and mainly low and intermediate level radioactive wastes arising from the maintenance work performed at the nuclear power plants.

The more than 6000 items of data received were processed using computers, generating tables, graphs and transport routes (among the most important and those that generate the highest impact are the routes for the transport of the low and intermediate level wastes from the six nuclear power plants to the disposal facility in El Cabril in Córdoba).

Figure 1 shows the most active transport routes in Spain, these being the A-2, A-3 and A-5 highways, the rest being considered lower transit or even secondary routes.

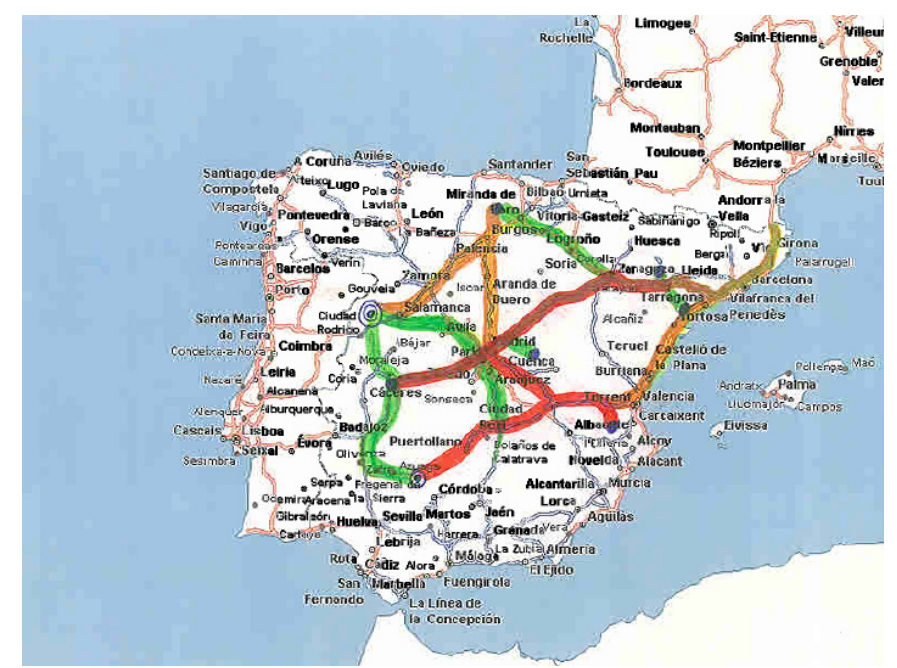

Figure 1 - Radioactive material transit routes.

Routes de transit des matières radioactives.

In total " 24 radioactive material transport routes" were considered. During the year studied, "243 transport operations" were performed and "12 865 km covered". The populations and provinces exposed, the total distance covered (124554 km. for all the shipments), the time taken (1 554 hours for all the transport operations) and the population per route were identified (example: the most significant route is from La Junquera on the border with France to Cofrentes NPP, with an exposed population of 10048888 inhabitants. The least significant route studied was that 
linking the fuel manufacturing facility in Juzbado to Almaraz NPP, with an exposed population of 756902 inhabitants). The national population is also considered in the study; in this last case only the towns located on the transport routes are taken into account, thus leaving out the regions of Galicia, Cantabria, the Basque Country, Navarre and Murcia, as well as a large part of Andalusia, since no transport operations are carried out on the roads in these areas.

Taking into account the probability of impact, which is indicated in the lower margin of Table I, "Radiological impact associated with the transport by road of radioactive material in Spain (2007)", it may be appreciated that the total environmental impact caused by ionising radiation, as the sum of all the transport operations performed by the time taken on the route and considering the levels of radiation at a distance of one metre from the transport vehicle, will amount to $46.64 \mathrm{mSv} \cdot \mathrm{y}^{-1}$, similar to the annual legal limit permitted in Spain for workers professionally exposed to ionising radiation $\left(50.00 \mathrm{mSv} \cdot \mathrm{y}^{-1}\right)$. It may be observed that the greatest impact, $42.00 \mathrm{mSv} \cdot \mathrm{y}^{-1}$, occurs in the transport of radioactive waste, the transport of fresh fuel implying a lower level of $15.92 \mathrm{mSv} \cdot \mathrm{y}^{-1}$.

However, in the emission of ionising radiation there is a process of attenuation depending on distance: as the distance from the source of emission increases, the level of radiation decreases in inverse proportion to the square of the distance (Tanarro, 1986). This attenuation occasionally leads to confusion with the natural ambient background radiation of the area.

Continuing with Table I, it may be seen that the dose potentially received by the most exposed individual, who will be the driver or passenger of a private vehicle coinciding on the route with the radioactive material transport vehicle and overtaking the latter on three occasions ( 15 seconds to overtake on three occasions on long journeys lasting 7 hours), will amount to $1.36 \mu \mathrm{Sv} \cdot \mathrm{y}^{-1}$. This is comparable with the findings of the study performed in Switzerland (Tunaboylu et al., 2001) which establishes that the radiation dose received by a person located 10 metres from a passing vehicle transporting spent nuclear fuel and travelling at a speed of $20 \mathrm{~km} / \mathrm{h}$. would amount to just $0.025 \mu \mathrm{Sv}$.

The impact on the "exposed group" located in the regions through which this type of transport passes (national impact), applied to the entire population residing in the different towns and provinces (23 419367 inhabitants) (INE, 2008), on the basis of the number and route of the transport operations and the distance from the vehicles involved, will be $1.1 \times 10^{-3} \mu \mathrm{S} \mathrm{y} \cdot{ }^{-1}$. This is also comparable with the environmental impact statement study on the transport of spent nuclear fuel to the Yucca Mountain deep geological disposal facility in the (U.S. DOE, 2002) which considers that the average dose for members of the public will be $0.005 \mu \mathrm{Sv} \cdot \mathrm{y}^{-1}$. 
RADIOLOGICAL IMPACT ASSOCIATED WITH THE TRANSPORT BY ROAD OF RADIOACTIVE

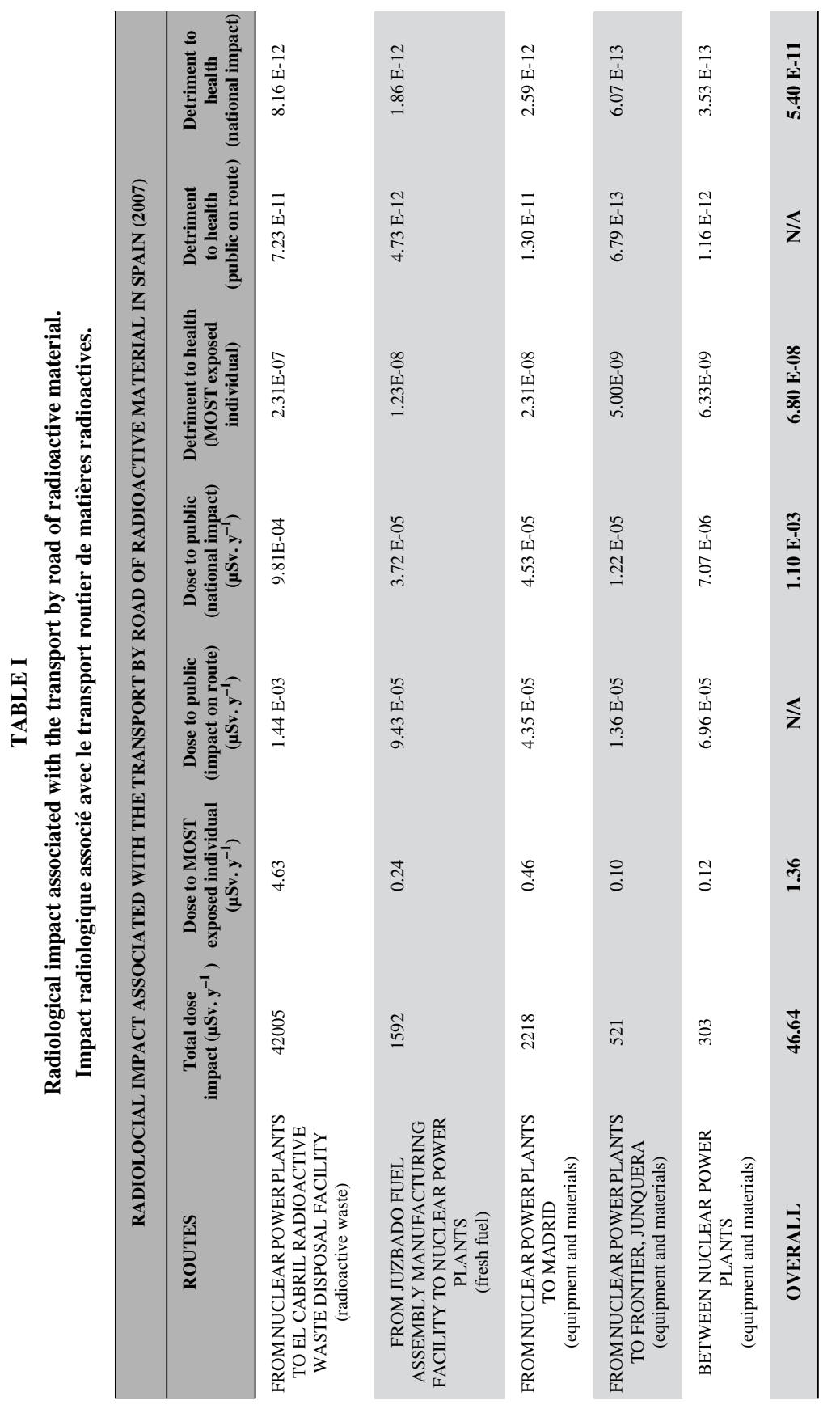

RADIOPROTECTION - VOL. 46 - N 3 (2011) 


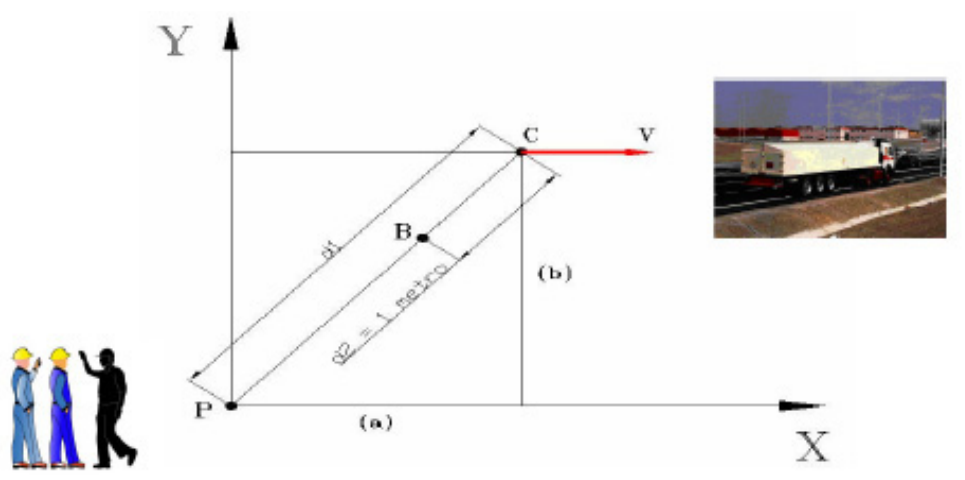

Figure 2 - Dose produced at a point by a moving vehicle transporting radioactive material.

Dose produite en un point par un véhicule en mouvement transportant des matières radioactives.

As the vehicle is generally in movement (Fig. 2), the dose rate produced at a point $(\mathrm{P})$ by a radioactive source located at a point $(\mathrm{C})$ will be:

$$
\mathrm{D}(\mathrm{P})=\mathrm{K} \frac{\mathrm{A}}{\mathrm{d}_{1}^{2}} \quad \mathrm{~A}=\text { Activity of source. }
$$

Likewise, the dose rate produced at (B) will be:

$$
\mathrm{D}(\mathrm{B})=\mathrm{K} \frac{\mathrm{A}}{\mathrm{d}_{2}^{2}} .
$$

As these may be related, the following will be obtained:

$$
\mathrm{D}(\mathrm{P})=\mathrm{D}(\mathrm{B}) \frac{\mathrm{d}_{2}^{2}}{\mathrm{~d}_{1}^{2}}
$$

If $d_{2}$ is considered to be equal to 1 metre, the dose rate at (B) becomes the transport index $(\mathrm{TI})$; in other words:

$$
\mathrm{D}(\mathrm{P})=\frac{\mathrm{IT}}{\mathrm{d}_{1}^{2}} ; \mathrm{d} 1^{2}=\mathrm{v}^{2} \cdot \mathrm{t}^{2}+\mathrm{b}^{2} .
$$

Consequently, the dose (D) at a point $(\mathrm{P})$ produced by the moving source may be obtained depending on the transport index (IT) and the distance between the radioactive material and this point. Furthermore, and with a view to maintaining dimensional coherence, a constant $\left(\mathrm{K}_{\mathrm{D}}\right)$, with a value of $\left(1 \mathrm{~m}^{2}\right)$, is introduced into 
the equation. Consequently, the dose produced by the moving source over the entire trajectory will be obtained by integrating the following expression:

$$
\int \mathrm{dD}(\mathrm{P})=\int_{0}^{\infty} \mathrm{K}_{\mathrm{D}} \cdot \mathrm{IT} / \int\left(\mathrm{v}^{2} \cdot \mathrm{t}^{2}+\mathrm{b}^{2}\right) \mathrm{dt}=\mathrm{K}_{\mathrm{D}} \cdot \mathrm{IT} / \mathrm{b} \cdot \mathrm{v}(\operatorname{arctg} \mathrm{v} \cdot \mathrm{t} / \mathrm{b})
$$

and as a result the following will be obtained: $\mathrm{D}(\mathrm{P})=\pi \cdot \mathrm{K}_{\mathrm{D}} \cdot \mathrm{IT} / \mathrm{b} \cdot \mathrm{v}$.

$$
\begin{aligned}
& \pi=3.1416 \\
& \mathrm{~K}_{\mathrm{D}}=\text { constant }\left(1 \mathrm{~m}^{2}\right) \\
& \mathrm{TI}=\text { transport index, level of radiation at one metre from the transport unit, } \\
& (\mu \mathrm{Sv} / \mathrm{h}) \\
& \mathrm{b}=\text { distance to the vehicle }(\mathrm{m}) \\
& \mathrm{v}=\text { speed of vehicle }(\mathrm{m} / \mathrm{h}) .
\end{aligned}
$$

This expression accurately calculates the gamma radiation dose that would be received by a group of people located at a known distance from a transport vehicle travelling at a fixed speed.

Although a generalised solution is adopted, without taking into account the precise proximity of the group to the transport vehicle or the variable speed of this vehicle, it is of interest to learn of the margin of error in the study performed.

If we focus on the impact generated on the general public (Tab. I), taking into account the following factors:

1. the total dose of $46.64 \mu \mathrm{Sv} \cdot \mathrm{y}^{-1}$ obtained, calculated on the basis of the radiation level at a distance of one metre from the vehicle (or $5 \mu \mathrm{Sv} \cdot \mathrm{h}^{-1}$, as the weighted average for all the types of transport on the different routes),

2. a speed of $90 \mathrm{~km} / \mathrm{h}$ (which is in keeping with the road safety regulations for this type of haulage),

3. an impact distance of 1000 metres (a distance within which might be located the bulk of the population of a major city such as Madrid, Barcelona or Zaragoza, which are significant cities through which such transport operations pass),

then, the following will be obtained:

$$
\mathrm{D}(\mathrm{P})=3.1416 \times 46.64 / 1000 \times 90000=1.6 \times 10^{-3} \mu \mathrm{Sv} \cdot \mathrm{y}^{-1}
$$

which is very similar to the dose obtained previously (Tab. I) of $1.1 \times 10^{-3} \mu \mathrm{Sv} \cdot \mathrm{y}^{-1}$.

We are aware that with this last calculation certain errors may have been made as regards distances, the constant speed of the vehicle and the location of the bulk of the population at the moment of passing of the vehicle. Nevertheless, as has already been pointed out, the objective pursued was to compare differences 
between the initial treatment of the data and its calculation using a more scientific process. Furthermore, it has been observed that the two sets of data are similar.

The probability of the most exposed individual suffering serious illness (cancer), the detriment to health resulting from exposure to ionising radiation amounts to $2.31 \times 10^{-7}$, this probability being approximately $10^{-12}$ (Tab. I) if considered at a national level. This figure is obtained as the quotient between the dose received by the general public and the probability of death by cancer of 5\% per Sievert in a population of all ages, as long as the dose and dose rate are low (ICRP, 1999).

In the epidemiological study of the possible effects of ionising radiation arising from the operation of the Spanish nuclear fuel cycle nuclear and radioactive facilities on the health of the population living in areas surrounding such installations (Nuclear Safety Council, 2010), the "effective dose" is proposed as an indicator of exposure, since this parameter brings benefits in a study of farreaching scope and spectrum and since furthermore several external exposure paths for ionising radiation are identified, along with others such as liquid and gaseous effluents that may be incorporated into the human organism.

In this paper, and since only external exposure to ionising radiation is dealt with, "distance" is proposed as the main indicator on the basis of the attenuation achieved in the process of emission, this being, in the opinion of the authors, the most appropriate approach in this case.

Overall dose impact: Value obtained from the contribution of all the shipments performed on all the routes.

Dose to most exposed individual (overtaking): 15 seconds $\times 3$ overtaking manoeuvres on the route: the individual is assumed to travel on the route at the same time as the shipment is performed.

Dose to public, impact on the route: Consideration is given to the population of all ages resident in the provinces through which the shipment passes.

Dose to public, national impact: Population of all ages in the national environment, subjected to impact.

Health detriment (death by cancer): the average value as regards the probability of death by cancer is $5 \%$ per Sievert in a population of all ages or $5 \mathrm{E}$ 08 per $\mu$ Sievert.

Although the units for description of the overall impact are proposed in equivalent dose $(\mu \mathrm{Sv})$, it would be more correct to express them in units of exposure or absorbed dose $(\mu \mathrm{Gy})$, since the dose may or may not be acquired by human beings (depending on whether or not they are in the area of exposure); however, as has been indicated, in the case of gamma emission the exposure is 
similar to absorbed dose and the same as equivalent dose. Consequently, as the values for the measurement of radiation level one metre from the transport vehicle are proposed in units of equivalent dose, those obtained in this study will in all cases be expressed in these units.

\section{Radiological impact calculation programme}

As a final contribution, a computer application for the treatment of the data studied is presented, along with a summary sheet: "Radiological Impact Associated with the Transport by Road of Radioactive Material in Spain".

This is perhaps the most interesting part of the work and marks a step forward in the study of these impacts, serving to complement the legally required documentation for this type of transport operation.

The radiation level at a distance of one metre from the transport vehicle being known, and with the route selected (Fig. 3) - which are data supplied by the shipper - the associated radiological impacts can be obtained (Fig. 4).

\section{Conclusions}

As an initial conclusion, it has been demonstrated that ionising radiation generated by the transport of radioactive materials from the nuclear fuel cycle in Spain is not

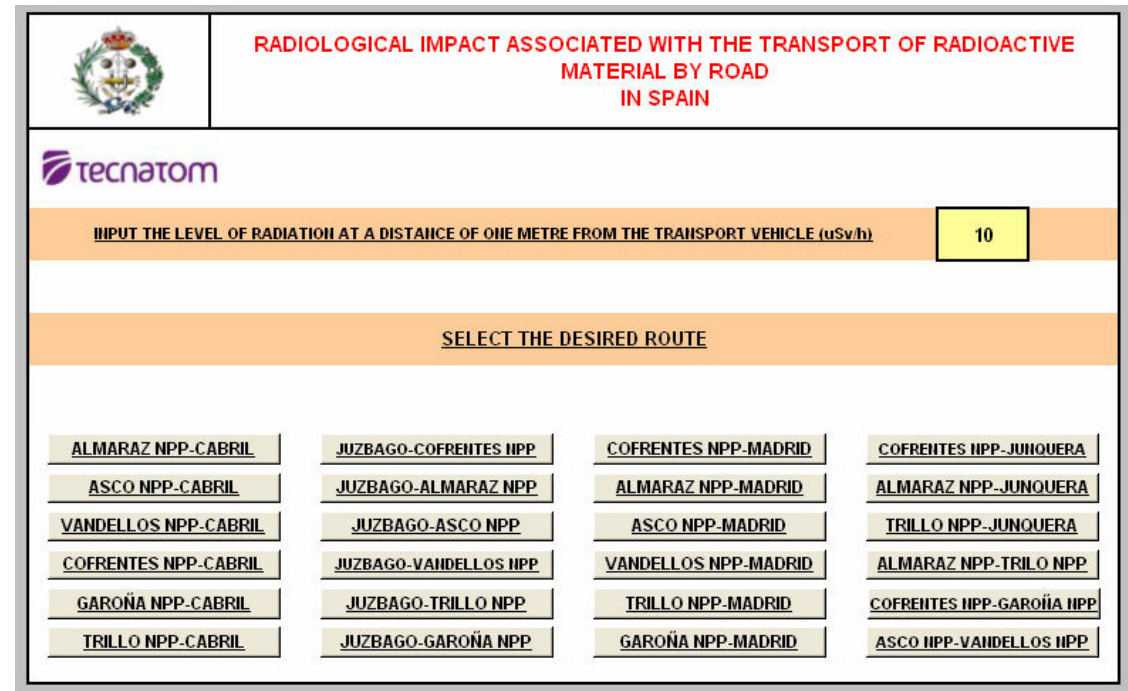

Figure 3 - Data input sheet.

Fiche d'entrée des données. 
J.A. CALLEJA, F. GUTIERREZ
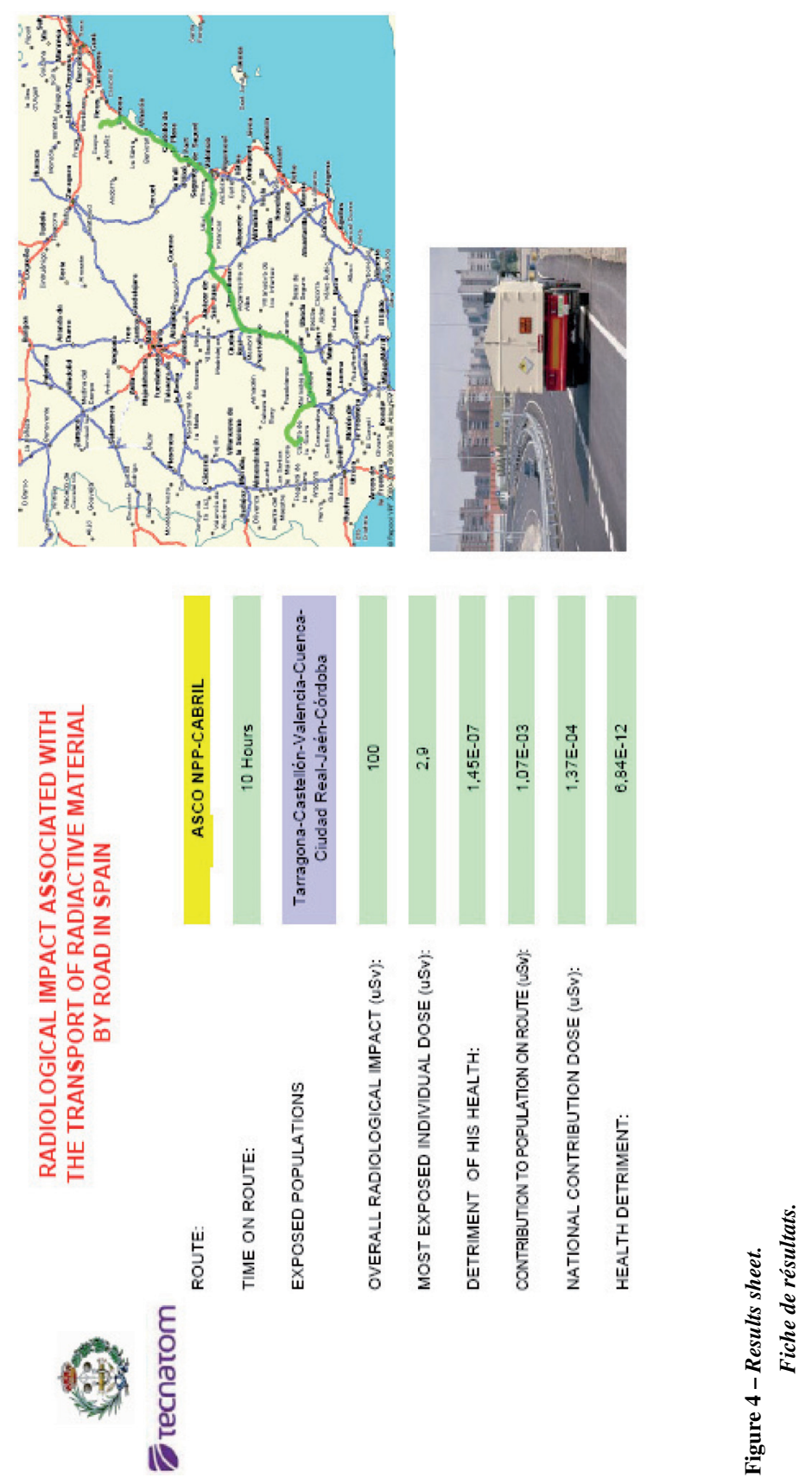
significant in terms of producing adverse effects for human health. Furthermore, the annual overall radiological impact is very low and has a negligible adverse impact on health.

Secondly, the routes used for this type of transport operations cover almost the entire national territory. Of the 24 existing routes, three are particularly active in terms of the density of shipments and of the significance of the associated radiological burden (these being the Extremadura A-5, Levante A-3 and Aragón A-2 motorways). This increases the associated radiological risk since the density of the traffic on these routes will be greater.

Acknowledgements. Our thanks go to the personnel of the radiological protection organisations of the Spanish nuclear power plants and to the members of the Tecnatom prevention service, who have proposed many of the data relating to the transport operations performed.

\section{REFERENCES}

ADR (2007) European Agreement on the international road transport of hazardous goods, BOE, supplement of January 21st 2007.

Chetty S. (1996) The case study method for research in small and medium-sized firms, International Small Business Journal 15, 73-85.

GRWP (2006) General Radioactive Waste Plan (VI), Approved by the Cabinet on July 23rd 2006.

ICRP Publication 60 (1999) Recommendations of the 'International Commission on Radiological Protection', Pergamon Press, Oxford (1991), Spanish translation by the Spanish Society of Radiological Protection, Madrid (1995).

INE (2008) Instituto Nacional de Estadística, URL: http://www.ine.es/ (accessed: 01/09/09).

Law 31/95 on Prevention of Occupational Risks (1995) BOE No. 269 of November 10th 1995.

Law 54/97 Electricity Industry Act, Official State Gazette of November 20th 1997.

Nuclear Safety Council and Institute of Health Carlos III (2010) Epidemiological study: Possible radiological impacts of nuclear and radioactive installations and fuel cycle on human health, URL: http://www.csn.es/index.php?option=com_content\&view=article\&id=14919 (accessed: 07/11/10).

Ortega X., Jorba B. (1988) Ionizing Radiations. Ed. Universidad Politécnica de Cataluña.

RD 566 on safety counsellors for the transport of hazardous goods by road, rail or ship (1999), BOE No. 254 of October 20th 1999.

Spanish (NPP) Nuclear power plants (1995),

URL:http://www.enresa.es/actividades y proyectos/raa/seguridad transporte raa (accessed: $10 / 12 / 09)$.

Tanarro A. (1986) Ionizing radiations: radioactive and X-ray facilities. Junta de Energía Nuclear.

Tunaboylu K., Plaifair A., Mariapillai N. (2001) Waste Transport and Public Safety, Technical Report PTR-01-03, Pangea Resources International, Baden, Switzerland.

U.S. DOE (2002) Final Environmental Impact Statement for a Geologic Repository for Disposal Spent Nuclear Fuel and High-Level Radioactive Wastes at Yucca Mountain, Nye County, Nevada, DOE/EIS-0250F, Washington, DC: Office of Civilian Radioactive Waste Management.

Yin R. (1994) Case study research: Design and methods. Sage Publishing, Beverly Hills. 